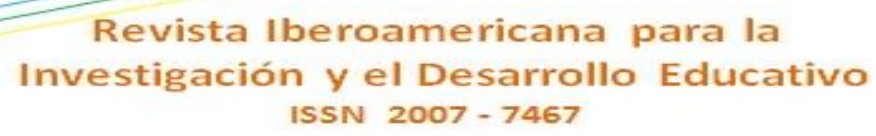

https://doi.org/10.23913/ride.v10i19.491

Artículos Científicos

\title{
Experiencias y retos de las mujeres pertenecientes al Sistema Nacional de Investigadores
}

Experiences and Challenges of Women Belonging to the Mexican National Researchers System

Experiências e desafios das mulheres pertencentes ao Sistema Nacional de Pesquisadores

Mónica del Carmen Meza Mejía

Universidad Panamericana, México mmeza@up.edu.mx https://orcid.org/0000-0001-6008-0215

Sara Elvira Galbán Lozano Universidad Panamericana, México sgalban@up.edu.mx https://orcid.org/0000-0002-9915-0441

Claudia Fabiola Ortega Barba Universidad Panamericana, México cortega@up.edu.mx https://orcid.org/0000-0003-2709-2024 


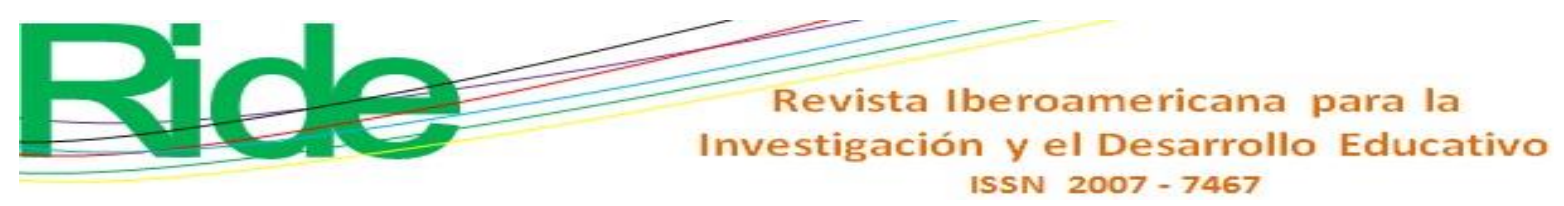

\section{Resumen}

La necesidad de acceso de las mujeres a la educación superior en México se hace patente desde tiempos remotos. Sin embargo, los primeros estudios sobre mujeres investigadoras en este país pueden rastrearse hace menos de 80 años; más reciente aún es el interés por conocer las vicisitudes por las que pasa una mujer en su carrera como investigadora, y en el contexto mexicano más concretamente como miembro del Sistema Nacional de Investigadores (SNI). Por ello, el estudio que aquí se presenta buscó comprender las experiencias e identificar los retos percibidos por las investigadoras pertenecientes al SNI para el ingreso, permanencia y promoción dentro del sistema.

Esta investigación se enmarcó en el paradigma interpretativo y para la recopilación de la información se utilizó la técnica de la entrevista semiestructurada. El análisis de la información se realizó mediante el método de las comparaciones constantes. A partir este se identificó que las participantes percibieron algunos retos a nivel personal e institucional, los cuales se reflejaron en las metacategorías construidas. La metacategoría de lo personal se dividió en dos categorías. Por un lado, el "ser investigadora", en donde se hace referencia a las experiencias que han vivido y que las han llevado a convertirse en investigadoras, además del significado que tiene para ellas dedicarse a esto y cómo se definen a sí mismas dentro de esta labor. Por otro lado, el papel de la familia, en la que se encontraron en un extremo las dificultades para lograr el balance entre la vida familiar y el trabajo, y en el otro la importancia del apoyo familiar en su carrera profesional. En la metacategoría de lo institucional, mientras tanto, las investigadoras se enfrentan a la cultura y políticas de dos instituciones diferentes: la universidad a la que están adscritas y el propio SNI. Dentro de los hallazgos más relevantes se puede decir que tanto en universidades públicas como privadas las mujeres se enfrentan al desafío de lograr un balance entre la vida familiar y el trabajo. Pasando al actuar profesional, se presentan dos retos comunes: las dificultades para la producción científica y la formación de nuevos investigadores. En las universidades públicas esto se debe en la mayoría de los casos a la falta de tiempo como consecuencia de actividades como la maternidad y la atención a la familia, mientras que, en las particulares, lo primero es consecuencia de los tiempos para la revisión, publicación e indexación, y lo segundo por la ausencia de posgrados orientados a la investigación en la universidad de adscripción.

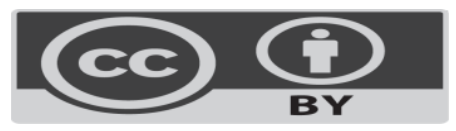




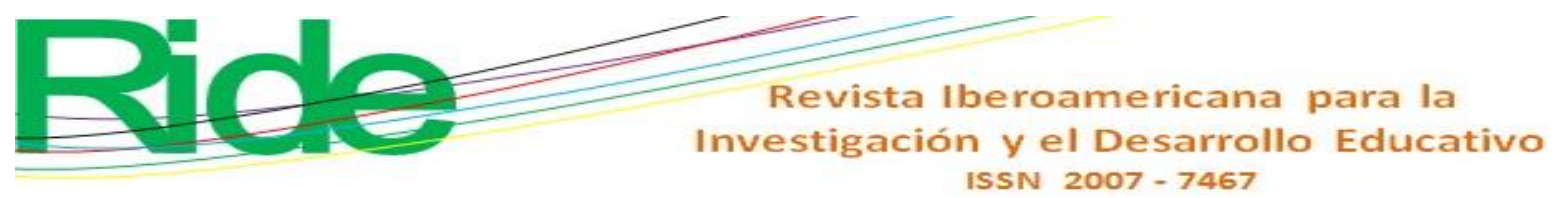

Palabras clave: condiciones institucionales de la investigación, mujeres investigadoras, políticas de la investigación.

\section{Abstract}

The urge of granting women access to education has been present ever science remote times. Nevertheless, the first publications about women researchers in Mexico can only be tracked back 80 years. The most recent interest has focused on the vicissitudes a woman faces in her career as a researcher, more specifically as a member of the National Researchers System (SNI). Thus, in the present study, it was intended to comprehend the experiences and identify the challenges these researchers face in order to become members of the system, keep their permanence and get promoted.

This is a qualitative research based upon the interpretative paradigm. Semi-structured interviews were used to collect the information and it was analyzed through the comparison method. It was found out that the participants perceived challenges at a personal and at an institutional level. Both levels served as metacategories. The personal challenges one was divided into two categories. The first one being "becoming a researcher", which refers to the hardships they faced in order to achieve the status and the significance it has for them. The second one centers in the role family has in their life, the difficulties they've encountered to balance it with their work, and the support they had to overcome these. In the metacategory of the institutional, meanwhile, the researchers had to face cultural and political differences of two different institutions: their university and the National Researchers System. The main findings were that women face challenges in balancing personal life and work and the importance the family has in balancing it out in both public and private institutions. With regards of the professional development, there are two common challenges: difficulty to produce new researches and the education of new researchers. In public universities, the reason is the lack of time due to maternity leaves and attention to their family in general, whilst at the private institutions there is a lack of time to revise and publish new papers and the fact that there are no postgraduate programs that are oriented towards research.

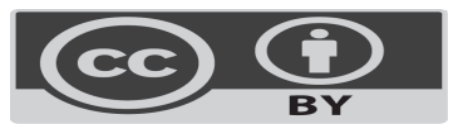




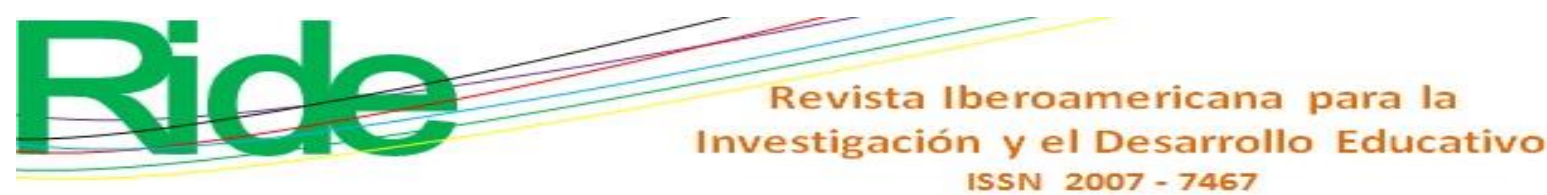

Keywords: research conditions, women researchers, research policies.

\section{Resumo}

A necessidade de acesso das mulheres ao ensino superior no México tem sido evidente desde os tempos antigos. No entanto, os primeiros estudos sobre pesquisadores do sexo feminino neste país podem ser rastreados há menos de 80 anos; Mais recente é o interesse em conhecer as vicissitudes que uma mulher atravessa em sua carreira como pesquisadora, e no contexto mexicano, mais especificamente, como membro do Sistema Nacional de Pesquisadores (SNI). Portanto, o estudo aqui apresentado buscou compreender as experiências e identificar os desafios percebidos pelos pesquisadores pertencentes ao SNI para admissão, permanência e promoção dentro do sistema. Esta investigação foi enquadrada no paradigma interpretativo e para a coleta de informações utilizou-se a técnica da entrevista semiestruturada. A análise das informações foi realizada utilizando o método de comparações constantes. A partir disso, identificou-se que os participantes percebiam alguns desafios em nível pessoal e institucional, refletidos nas metacategorias construídas. A metacategoria do pessoal foi dividida em duas categorias. De um lado, o "ser pesquisador", onde é feita referência às experiências que viveram e que as levaram a se tornar pesquisadores, além do significado que tem para elas se dedicarem a isso e como se definem dentro de si. este trabalho. Por outro lado, o papel da família, no qual as dificuldades foram encontradas para alcançar um equilíbrio entre a vida familiar e o trabalho, e, de outro, a importância do apoio familiar em sua carreira profissional. Na metacategoria institucional, entretanto, os pesquisadores enfrentam a cultura e as políticas de duas instituições diferentes: a universidade à qual estão ligadas e o próprio SNI. Entre as conclusões mais relevantes, pode-se dizer que tanto nas universidades públicas quanto nas privadas, as mulheres enfrentam o desafio de alcançar um equilíbrio entre a vida familiar e o trabalho. Passando a atuar profissionalmente, há dois desafios comuns: as dificuldades para a produção científica e a formação de novos pesquisadores. Nas universidades públicas isso é devido, na maioria dos casos, à falta de tempo como resultado de atividades como maternidade e cuidado familiar, enquanto no caso de indivíduos privados, o primeiro é uma 

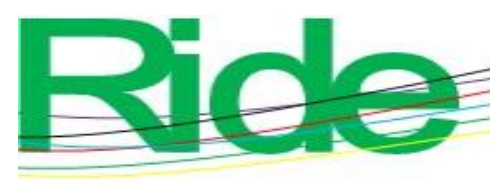

Revista Iberoamericana para la Investigación y el Desarrollo Educativo ISSN $2007-7467$

conseqüência dos tempos de revisão, publicação e indexação, e o segundo, pela ausência de cursos de pós-graduação voltados à pesquisa na universidade de atribuição.

Palavras-chave: condições institucionais de pesquisa, mulheres pesquisadoras, políticas de pesquisa.

Fecha Recepción: Noviembre 2018

Fecha Aceptación: Mayo 2019

\section{Introducción}

La necesidad de acceso de las mujeres a la educación superior en México se hace patente desde tiempos remotos. Si bien entre los siglos XVI al XIX se menciona solo a Micaela Hernández como científica y docente de física en la Escuela de Artes y Oficios para Mujeres en la capital del país (González, 2006), la polémica de la educación profesional de la mujer inicia por lo menos desde la gestión de la Secretaría de Instrucción Pública y Bellas Artes en el gobierno de Sebastián Lerdo de Tejada (1872-1876).

Lo anterior con la solicitud de ingreso a la universidad y recepción profesional de Matilde Montoya, la primera mujer que se tituló en la Escuela Nacional de Medicina en 1887, sin pasar por alto que ya en 1886 Margarita Chorné y Salazar había obtenido el título de una profesión independiente (dentista), también en la Escuela Nacional de Medicina (Díaz de Kuri, 2009).

En la coyuntura de la Revolución mexicana, se inaugura la Universidad Nacional, la Escuela de Altos Estudios y se celebra el primer ciclo de conferencias organizado por el Ateneo de la Juventud que amplían las oportunidades de educación profesional de las mujeres (Cano, 2010). En 1912 se celebró el Primer Congreso Científico Mexicano, donde la asistencia femenina fue significativa (Piñera, 2002).

A finales del siglo XIX y principios del XX, las ideas que cuestionaban la participación de la mujer en la ciencia (Cano, 2010) fueron superadas gracias a mujeres como Aline Schunemann, investigadora emérita de la Universidad Nacional Autónoma de México (UNAM), cuarta mujer en titularse de la carrera Médica Veterinaria y Zootecnia, con 70 años dedicados a la investigación y con 94 años de edad, quien afirma "la ciencia no es cuestión de género, es cuestión de que se trabaje

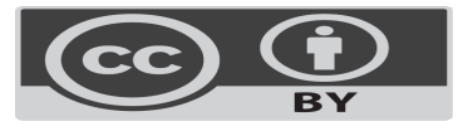




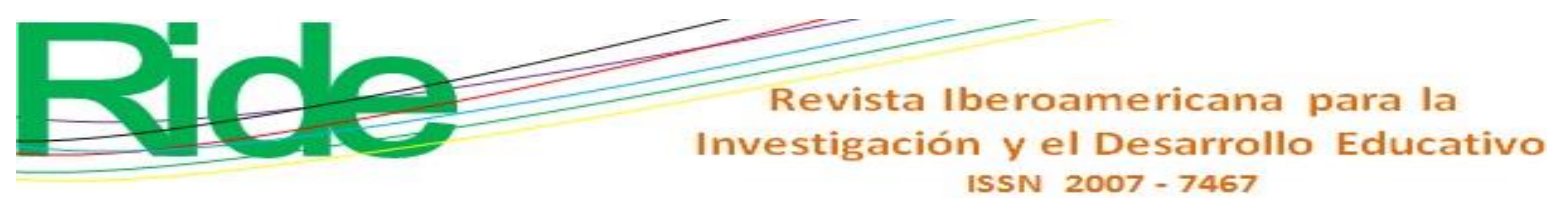

bien, si uno hace bien las cosas, uno se gana su lugar sin importar si es hombre o mujer" (Sánchez, 15 de enero de 2015, párr. 21).

Es así como los primeros estudios sobre mujeres investigadoras en México pueden rastrearse hace menos de 80 años. En los años 40 del siglo XX, se realizaron trabajos en torno a las primeras mujeres que se titularon en las licenciaturas en Física y Matemáticas en la Facultad de Ciencias de la UNAM y las que ingresaron a la Sociedad Matemática Mexicana. Además de rescatar antologías de mujeres universitarias, que narran una síntesis biográfica de siete científicas mexicanas (González, 2006).

Sin embargo, es más reciente el interés por conocer las vicisitudes por las que pasa una mujer en su carrera como investigadora. En este sentido, se encuentra el trabajo de Muñiz y Ramos (2019), en donde se muestra la presión que muchas veces sufren las mujeres investigadoras en relación con la maternidad. Además del estudio realizado por Castillo (2018), que tiene como objetivo "mostrar las diferencias visibles, así como develar las diferencias invisibles, presentes en las actividades relacionadas con la investigación, la ciencia y la tecnología (...) de las docentes investigadoras de la Universidad Nacional de San Agustín de Arequipa [Perú]” (p. 79). En esta se evidencia que las aportaciones de las mujeres tienen menos valía que la de los varones.

En cuanto a investigaciones específicas sobre mujeres pertenecientes al Sistema Nacional de Investigadores (SNI), Ruiz (2012) asienta la necesidad de generar políticas con perspectiva de género al interior del sistema, "pues tanto la permanencia como la promoción de las científicas investigadoras mexicanas es complicada" (p. 48). Aunado a lo anterior, se encuentra también la iniciativa llevada a cabo en 2014 en la Benemérita Universidad Autónoma de Puebla (BUAP), que convocó al Primer Congreso de Investigadoras SNI y cuyas reflexiones, conclusiones y propuestas quedaron plasmadas en el texto coordinado por Angélica Mendieta en 2015. De manera más reciente, se encuentra el trabajo de Ranero (2018), en donde se revisa la diferenciada integración de académicas en el SNI, así como la segmentación laboral que caracteriza a la academia mexicana.

Mención aparte requiere la investigación realizada por Macías e Islas (2018), quienes rescatan y posicionan a las tecnologías de la información y de la comunicación (TIC) como medios de empoderamiento de las mujeres investigadoras pertenecientes al SIN.

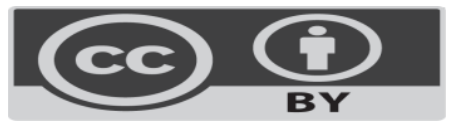



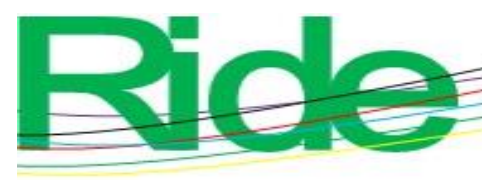

Revista Iberoamericana para la Investigación y el Desarrollo Educativo ISSN 2007 - 7467

Es así como, aunque se han publicado investigaciones en torno a la profesión académica y específicamente sobre mujeres investigadoras (Grediaga, 2001; Galaz, Gil, Padilla, Sevilla, Arcos y Martínez, 2012; Castañeda y Ordorika, (2015); Ordorika, 2015), se han encontrado pocas referencias de las pertenecientes al SNI adscritas a instituciones de educación superior particulares.

Por todo lo anteriormente mencionado, el estudio que aquí se presenta busca comprender las experiencias e identificar los retos percibidos por las investigadoras pertenecientes al SNI para el ingreso, permanencia y promoción dentro del sistema.

\section{Marco de referencia}

El SNI es una agrupación en la que están representadas las disciplinas científicas que se practican en el país y cubre una gran mayoría de las instituciones de educación superior e institutos y centros de investigación que operan en México. Se creó por decreto presidencial el 26 de julio de 1984, para reconocer mediante el nombramiento de investigador nacional y su respectivo estímulo económico el trabajo de aquellos investigadores dedicados a producir conocimiento científico y tecnológico.

El principal objetivo del SNI es promover y fortalecer, mediante la evaluación de pares, la calidad de la investigación científica y tecnológica y la innovación que se produce en el país. Asimismo, pretende contribuir a la formación y consolidación de investigadores con conocimientos científicos y tecnológicos del más alto nivel (Diario Oficial de la Federación [DOF], 2018).

Las disciplinas de afiliación se organizan por áreas del conocimiento, a saber:

I. Físico-Matemáticas y Ciencias de la Tierra.

II. Biología y Química.

III. Medicina y Ciencias de la Salud.

IV. Humanidades y Ciencias de la Conducta.

V. Ciencias Sociales.

VI. Biotecnología y Ciencias Agropecuarias.

VII. Ingenierías (DOF, 2018, Cap. IV, art. 12). 


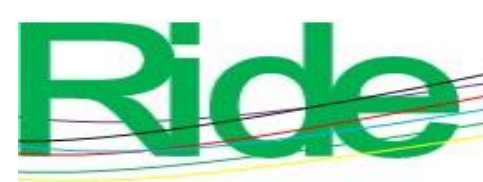

Revista Iberoamericana para la Investigación y el Desarrollo Educativo ISSN 2007-7467

La evaluación de los aspirantes a pertenecer al SNI y la permanencia de los ya aceptados se realiza mediante comisiones evaluadoras (miembros del SNI integrados ex professo).

El nombramiento de investigador nacional responde a tres categorías: Candidato; Investigador Nacional con tres niveles, e Investigador Nacional Emérito (DOF, 2018, cap. XIV, art. 46). Cabe decir que, aunque hay requisitos generales para el ingreso/permanencia al SNI, cada área del conocimiento presenta algunas particularidades. De igual modo, el estímulo económico asociado al reconocimiento público que otorga el Gobierno federal por medio del SNI a investigadores se aplica según la categoría o nivel.

En la historia del SNI, los integrantes han crecido de manera exponencial, toda vez que han pasado de 1396 en 1984 a 27186 en 2017, lo cual evidencia, en 33 años, un crecimiento multiplicado casi por 20 de su número original. Igualmente se ha suscitado una tendencia hacia la descentralización, pues mientras que en $200939.5 \%$ de los investigadores SNI estaban adscritos a instituciones de la capital mexicana, en 2010 se redujo a 38 \% (Didou y Gérard, 2010), y más actualmente solo 31.63 \% se ubican en la Ciudad de México. En este contexto, son las instituciones de educación superior públicas quienes concentran el mayor número de investigadores, entre las que destacan la UNAM con 4598, el Instituto Politécnico Nacional (IPN) con 1200 y la Universidad Autónoma Metropolitana (UAM) con 1170, que juntas representan $25.61 \%$ de los investigadores miembros del SNI en 2017.

Ahora bien, en cuanto a sexo, el número de mujeres es hasta ahora menor al número de hombres, y aunque hay una perceptible feminización ingente de los integrantes del SNI (Didou y Gérard, 2010), el número sigue siendo inferior, como lo muestran las siguientes cifras: en 1984, de un total de 1377 investigadores SNI, 283 eran mujeres, lo que representaba $20.5 \%$ de la población total. Para 2004, con un crecimiento sustancial de investigadores de más de $700 \%$, se reportaban 10140 integrantes del sistema, de los cuales 3332 mujeres, casi $33 \%$ del total de investigadores. Lo anterior permite mostrar que la participación de las mujeres ascendió en 20 años de $20.5 \%$ a 33 \% (Sánchez, 2015). Para 2014, 30 años después, los números reflejaban un incremento mayor al registrase 7443 mujeres de 21379 miembros del SNI (García, 2015).

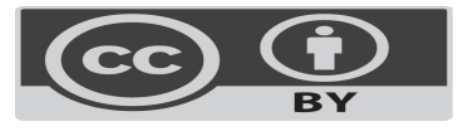



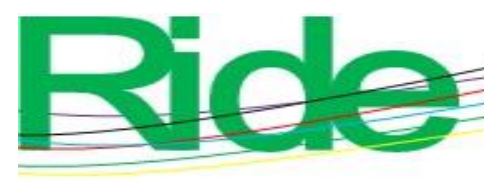

Revista Iberoamericana para la Investigación y el Desarrollo Educativo ISSN $2007-7467$

Con el corte hecho al 1 de febrero de 2018, a partir de la información que reporta la base de datos de beneficiarios del SNI de 2017, se citan un total de 27186 miembros; de ellos, 9945 son investigadoras, es decir, $36.58 \%$. Porcentaje menor que el de los investigadores (63.42\%), no obstante que ha habido un incremento notorio respecto de las 283 investigadoras que había en 1984.

Las 9945 investigadoras tienen presencia en la mayoría de las categorías o niveles del SNI, como se puede observar en la figura 1. En el nivel I se concentra más de la mitad de ellas, seguido por las ubicadas en el nivel Candidato.

Figura 1. Distribución de las investigadoras del SNI por categoría o nivel

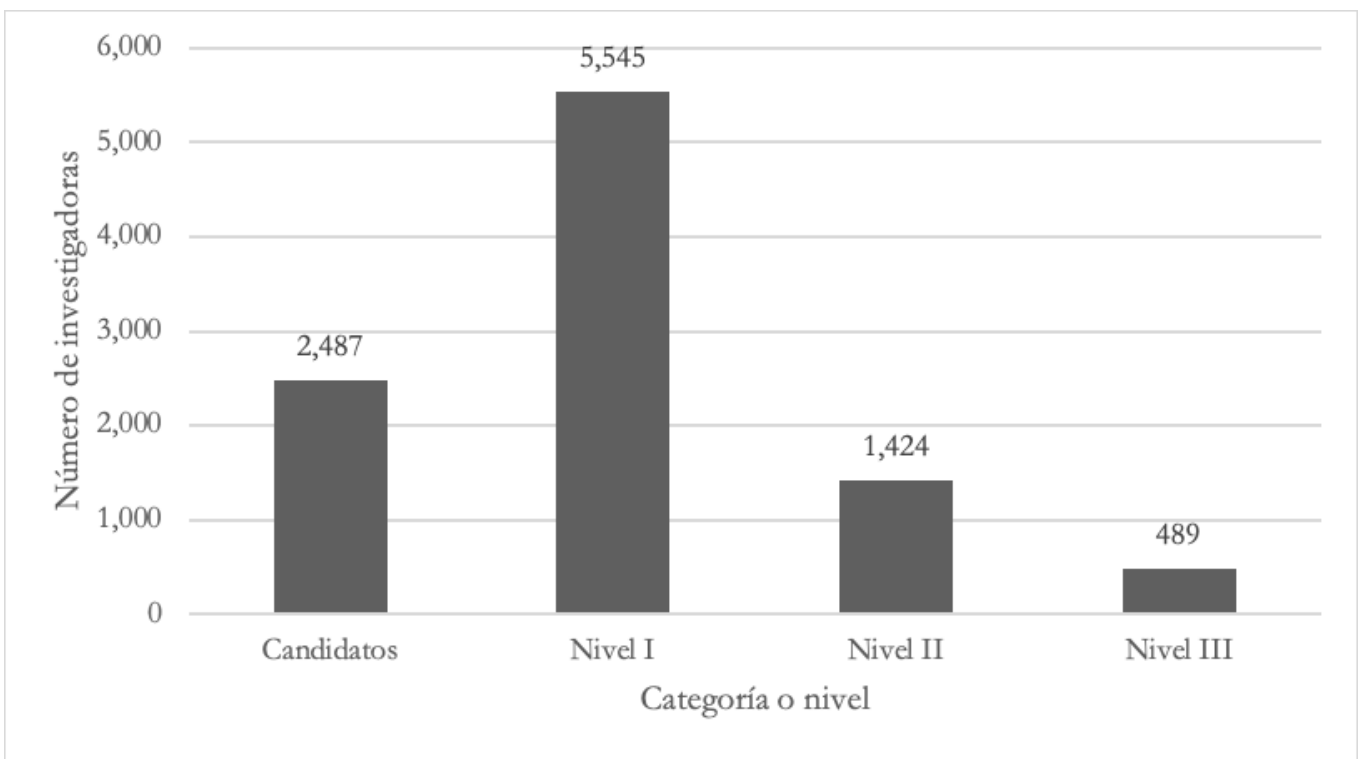

Fuente: Elaboración propia con base en el SNI (2017)

En cuanto a las áreas del conocimiento, las investigadoras SNI se distribuyen en todas ellas de la manera como se presenta en la figura 2. Destaca la mayor concentración en el área IV. Humanidades y Ciencias de la Conducta, en contraste con las áreas I. Físico-Matemáticas y Ciencias de la Tierra y VII. Ingenierías. 


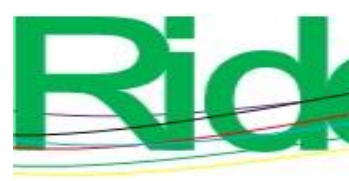

\section{Revista Iberoamericana para la Investigación y el Desarrollo Educativo ISSN 2007 - 7467}

Figura 2. Distribución de las investigadoras del SNI por área de conocimiento

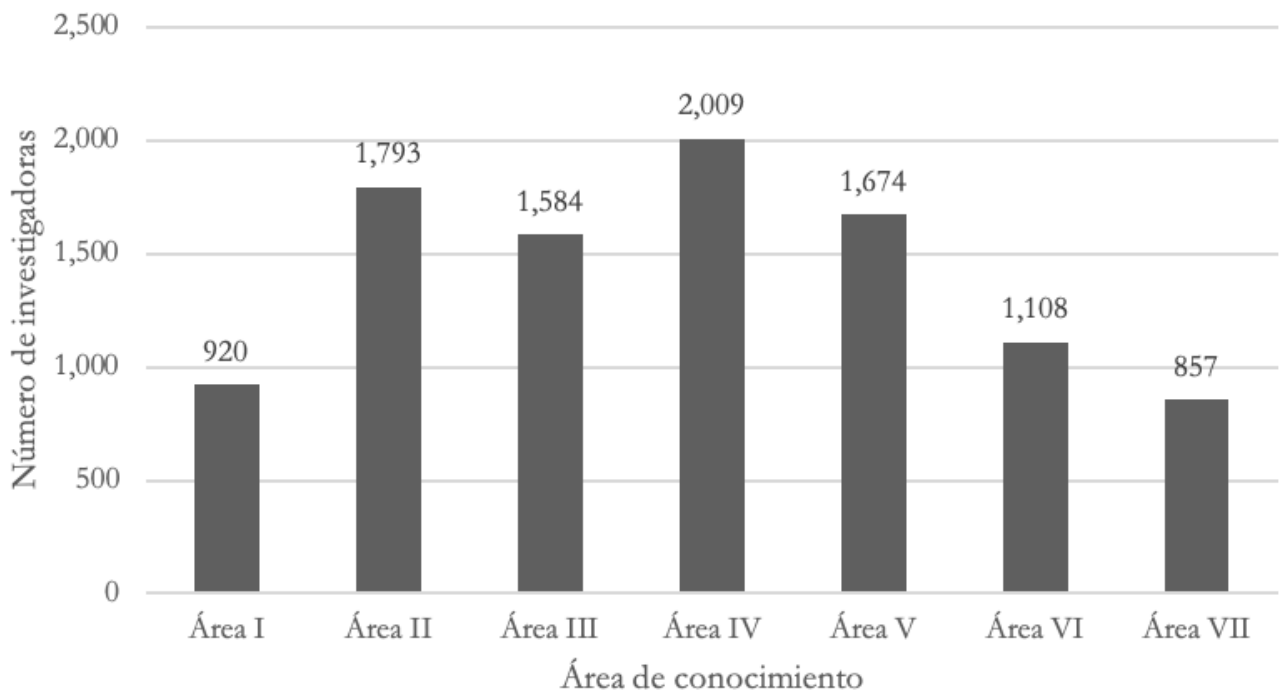

I. Físico-Matemáticas y Ciencias de la Tierra; II. Biología y Química; III. Medicina y Ciencias de la Salud; IV. Humanidades y Ciencias de la Conducta; V. Ciencias Sociales; VI. Biotecnología y Ciencias Agropecuarias; VII. Ingenierías.

Fuente: Elaboración propia con base en el SNI (2017)

Si se comparan los datos de las investigadoras con las de los investigadores, por categoría o nivel del SNI, se tiene que ambos se distribuyen de manera similar en el nivel I y el II. Mientras que en el nivel III la distancia es notoria (ver tabla 1).

Tabla 1. Distribución de las investigadoras e investigadores SNI por categoría o nivel

\begin{tabular}{|c|c|c|c|c|c|}
\hline & Candidato & Nivel 1 & Nivel 2 & Nivel 3 & Total \\
\hline Investigadoras & 2487 & 5545 & 1424 & 489 & 9945 \\
\hline$\%$ & $8.9 \%$ & $20.39 \%$ & $5.23 \%$ & $1.79 \%$ & $36.31 \%$ \\
\hline Investigadores & 3330 & 9117 & 3028 & 1766 & 17241 \\
\hline$\%$ & $12.2 \%$ & $33.53 \%$ & $11.13 \%$ & $6.49 \%$ & $63.35 \%$ \\
\hline & & & & & 27186 \\
\hline
\end{tabular}

Fuente: Elaboración propia con base en el SNI (2017) 

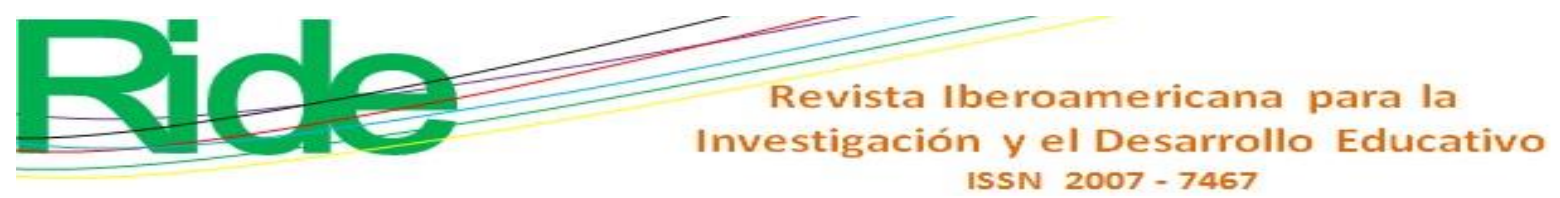

Por área de conocimiento, los investigadores y las investigadoras del SNI se distribuyen como se presenta en la figura 3, donde $\mathrm{N}=27,186$. En el caso de las segundas, el área IV. Humanidades y Ciencias de la Conducta concentra el mayor número; mientras que respecto a los primeros hay mayor concentración en el área I. Físico-Matemáticas y Ciencias de la Tierra.

Figura 3. Distribución de las investigadoras y los investigadores del SNI por área de

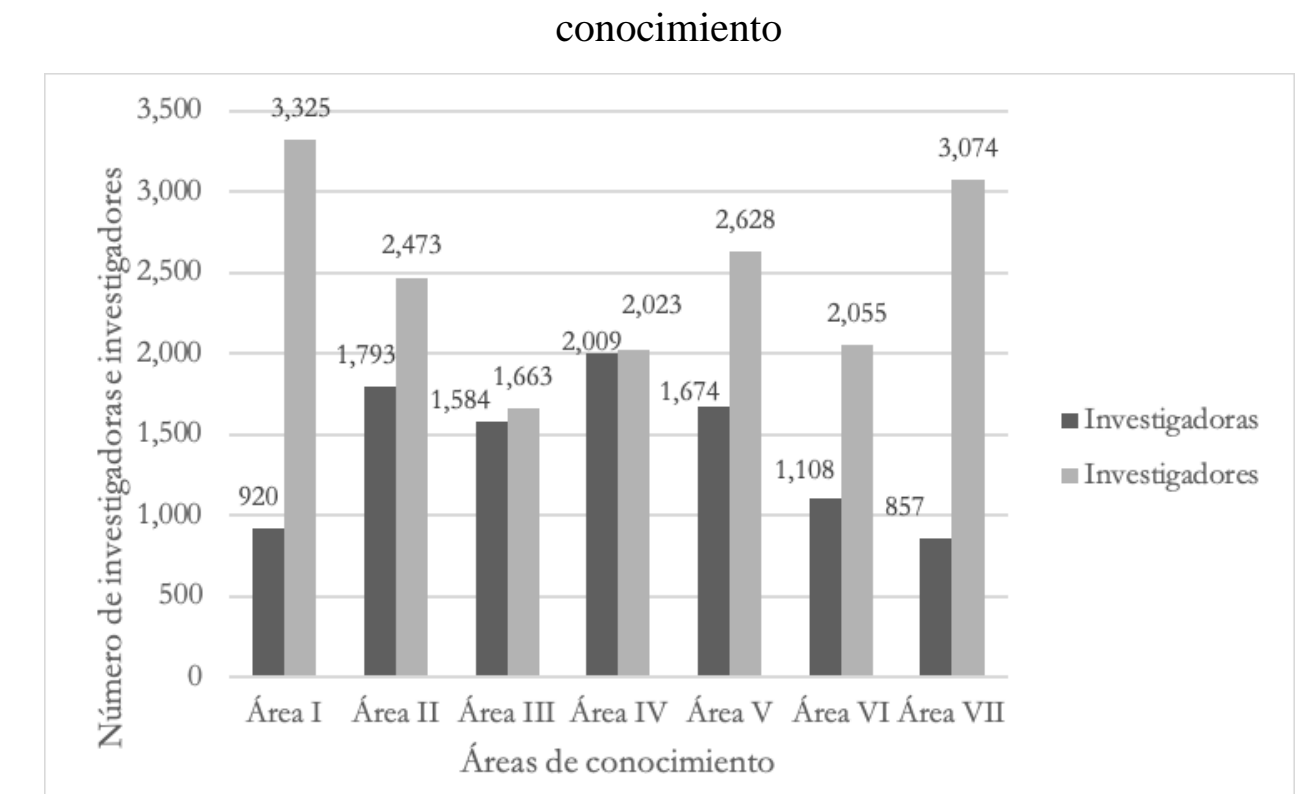

I. Físico-Matemáticas y Ciencias de la Tierra; II. Biología y Química; III. Medicina y Ciencias de la Salud; IV. Humanidades y Ciencias de la Conducta; V. Ciencias Sociales; VI. Biotecnología y Ciencias Agropecuarias; VII. Ingenierías

Fuente: Elaboración propia con base en el SNI (2017)

Respecto a las instituciones de adscripción de las investigadoras, para el 2015 Eugenio Cetina, director del SNI, refería los datos que se muestran en la tabla 2. En ella se ubica a 888 universidades particulares, que representan $4 \%$ del total de las instituciones citadas, y un crecimiento de $302 \%$ respecto al año 2000, en donde solo había 221 universidades particulares; es decir, $3.1 \%$ del total de las universidades adscritas entonces. 
Tabla 2. Comparativo de número total de SNI en las instituciones de adscripción

\begin{tabular}{|c|c|c|c|}
\hline Sector & 2000 & 2015 & Crecimiento \% \\
\hline USES & 1435 & 8383 & 484 \\
\hline IES Fed & 3646 & 7471 & 105 \\
\hline $\mathrm{CPI}-\mathrm{C}$ & 750 & 1883 & 151 \\
\hline SSFed & 546 & 1480 & 171 \\
\hline UPart & 221 & 888 & 302 \\
\hline CPI & 374 & 741 & 98 \\
\hline Ext & 63 & 611 & 870 \\
\hline TNM + ITD & 92 & 565 & 514 \\
\hline Otras & 336 & 1294 & 285 \\
\hline TOTALES & 7463 & 23316 & 212 \\
\hline \multicolumn{4}{|c|}{$\begin{array}{l}\text { USES: Universidades Subsectorizadas en la SES. IES Fed.: UNAM, UAM, IPN, Cinvestav, Colmex, UPN } \\
\text { CPI - C: Centros Públicos de Investigación Conacyt. SSFed: Institutos Nacionales de Salud, SSA, IMSS } \\
\text { Issste... UPart.: IES Particulares. CPI: Otros Centros Públicos de Investigación (IIE, IMP...). Ext. } \\
\text { Instituciones en el Extranjero. TecNM: Institutos Tecnológicos Estatales (Desc. Gob. Edo.). Otras }\end{array}$} \\
\hline
\end{tabular}

Fuente: Cetina (2015)

En la tabla 3 se clasifica el número de investigadoras considerando siete universidades particulares. En ella, el Instituto Tecnológico y de Estudios Superiores de Monterrey (Itesm) tiene el mayor número de investigadoras y la Universidad del Valle de México (UVM) el menor. Mientras que la Universidad Panamericana (UP), contexto de esta investigación, cuenta con 28 investigadoras a febrero de 2018, lo cual representa $8.68 \%$ de las investigadoras adscritas a las universidades particulares enlistadas, por lo que ocupa el cuarto lugar en orden descendente. 
Tabla 3. Número de investigadoras en instituciones de educación superior particulares

\begin{tabular}{|c|c|c|c|}
\hline & Institución de educación superior & Número de investigadoras & $\%$ \\
\hline 1 & Itesm & 173 & 53.5 \\
\hline 2 & Universidad Iberoamericana & 48 & 14.88 \\
\hline 3 & Universidad Anáhuac & 39 & 12.08 \\
\hline \hline 4 & UP & 28 & 8.68 \\
\hline 5 & Instituto Tecnológico Autónomo de & 16 & 4.95 \\
& México & 13 & 4.04 \\
\hline 6 & Universidad La Salle & 6 & 1.87 \\
\hline 7 & UVM & 323 & 100 \\
\hline
\end{tabular}

Fuente: Elaboración propia con base en el SNI (2017)

Una vez analizado el lugar que ocupan las mujeres dentro del SNI y específicamente en las universidades particulares, a continuación se presenta la metodología de este estudio y el contexto específico de esta investigación.

\section{Marco metodológico}

Esta investigación se enmarca en el paradigma interpretativo y el enfoque cualitativo, con una perspectiva fenomenológica. Como afirman Merriam y Tisdell (2016), los estudios cualitativos "buscan descubrir y comprender un fenómeno, un proceso o las perspectivas y cosmovisiones de las personas involucradas, cómo las personas interpretan sus experiencias y qué significado les atribuyen” (p. 15). En este caso, se busca responder a la siguiente pregunta: ¿Cuáles son las experiencias y los retos a los que se enfrentan las investigadoras pertenecientes al SNI para el ingreso, permanencia y promoción dentro del sistema? Es decir, lo que interesa resaltar es la mirada de las investigadoras. 


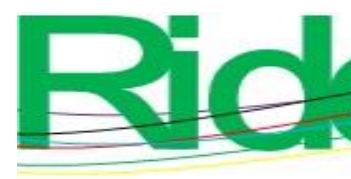

Revista Iberoamericana para la Investigación y el Desarrollo Educativo ISSN $2007-7467$

Se consideró recurrir a una perspectiva fenomenológica, pues a partir de esta se busca conocer la realidad tal como otros la ven y experimentan (Taylor y Bogdan, 1994). Patton (2015) explica que la fenomenología busca comprender cómo las personas describen e interpretan las experiencias. De esta forma, se examina el modo en el que otros experimentan el mundo. Lo que importa es lo que las personas perciben como relevante, pues se considera preferente el significado que los propios protagonistas dan a sus acciones (Tójar, 2006). Asimismo, desde esta perspectiva, se considera que los seres humanos están vinculados con su mundo y, por ende, se pone énfasis en la experiencia vivida, la cual aparece en el contexto de las relaciones con objetos, personas, sucesos y situaciones (Galeano, 2004).

\section{Contexto de investigación}

La UP, en 2018, contaba con 113 profesores pertenecientes al SNI, de los cuales 85 eran hombres y 28 mujeres, es decir, $24.77 \%$. La edad promedio de las investigadoras estaba en los 47 años, semejante al promedio nacional según el estudio de Didou y Gérard (2010), y había un rango de 70 a 32 años, edad esta última que tenía la investigadora más joven. En cuanto a la formación académica de las investigadoras, $43 \%$ realizó estudios de doctorado en universidades públicas, mientras que $57 \%$ en instituciones de educación superior particulares. Asimismo, $43 \%$ de las investigadoras estudió en universidades extranjeras y $57 \%$ en instituciones nacionales.

El año de ingreso al SNI de las investigadoras de la UP inició desde el año 2000. Y justamente se aprecia un mayor ingreso a partir de entonces, lo que es un reflejo, primero, de las políticas del Consejo Nacional de Ciencia y Tecnología (Conacyt), que a partir del 2008 aporta a investigadores adscritos a instituciones de educación superior particulares $30 \%$ del estímulo económico, y desde el 2014 aporta el 100 \% de este. Y, en segundo lugar, al fortalecimiento de las políticas de la UP para favorecer la investigación reconocida por pares y certificada por el Conacyt (UP, 2018).

En cuanto al nivel que ocupan dentro del SNI, 10 son candidatas (36 \%), 14 son nivel I (50 \%) y 4 son nivel II (14 \%). No se tiene en la UP todavía ninguna investigadora en el nivel III (véase figura 4), como sí sucede en el caso de los investigadores, ya que hay tres representantes de la UP en el máximo nivel (figura 5).

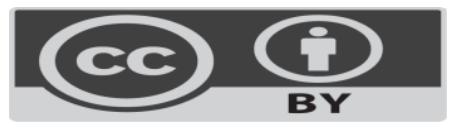




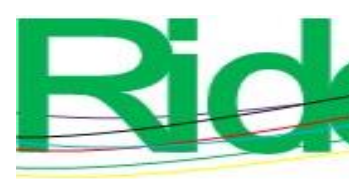

\section{Revista Iberoamericana para la Investigación y el Desarrollo Educativo ISSN $2007-7467$}

Figura 4. Distribución de las investigadoras SNI de la UP por categoría o nivel

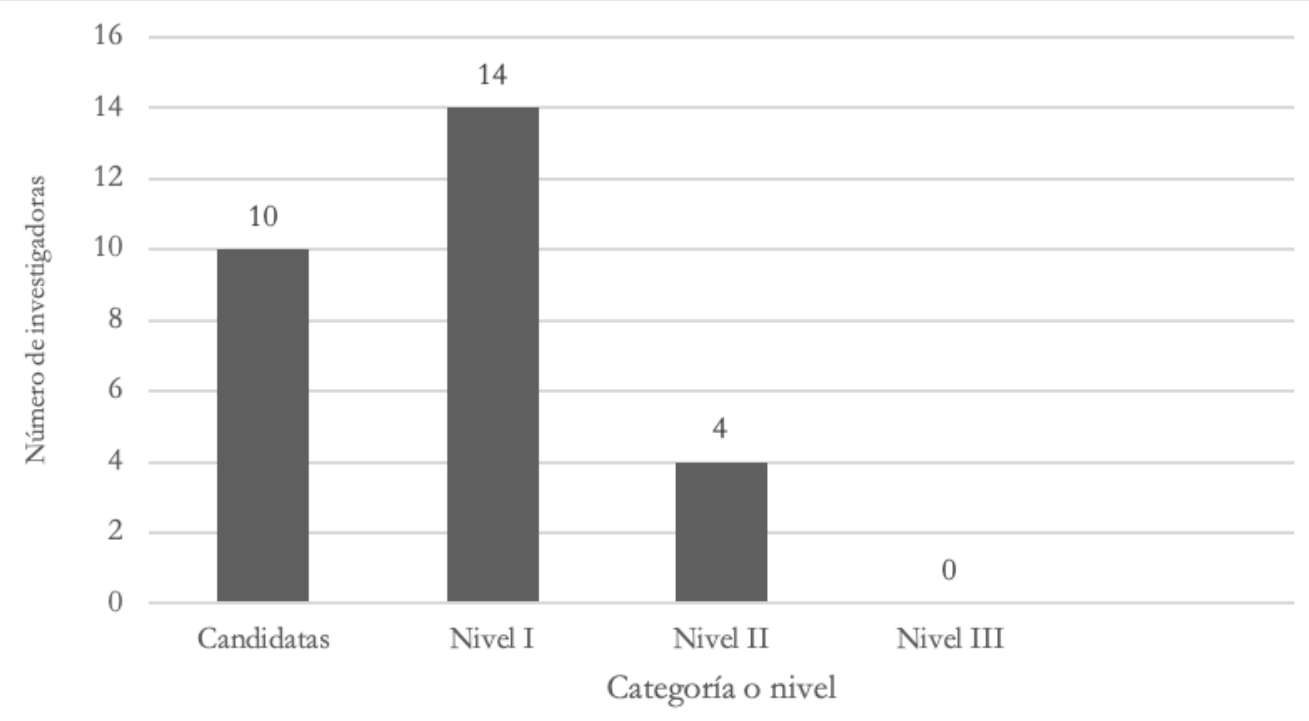

Fuente: Elaboración propia con base en la UP (2018)

Figura 5. Distribución de los investigadores SNI de la UP por categoría o nivel

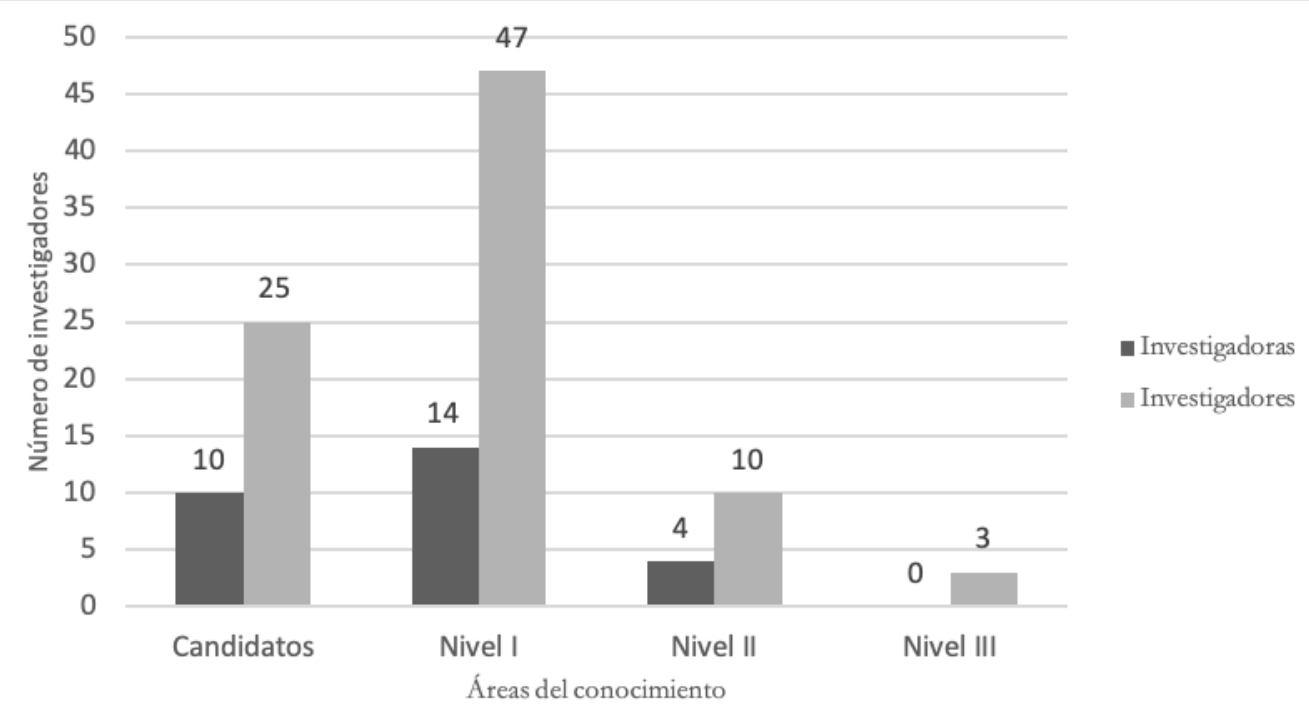

Fuente: Elaboración propia con base en la UP (2018) 

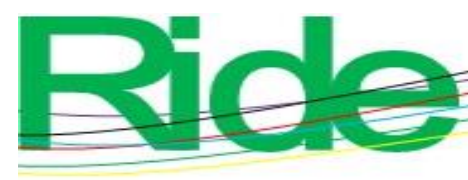

Revista Iberoamericana para la

Investigación y el Desarrollo Educativo

ISSN $2007-7467$

En la figura 6, por su parte, se muestra el área del conocimiento a la que pertenecen las investigadoras. Como se aprecia, hay una mayor concentración en las áreas IV. Humanidades y Ciencias de la Conducta y V. Ciencias Sociales, y un menor número en las áreas I. FísicoMatemáticas y Ciencias de la Tierra y VII. Ingenierías.

Figura 6. Distribución de las investigadoras SNI de la UP por áreas de conocimiento

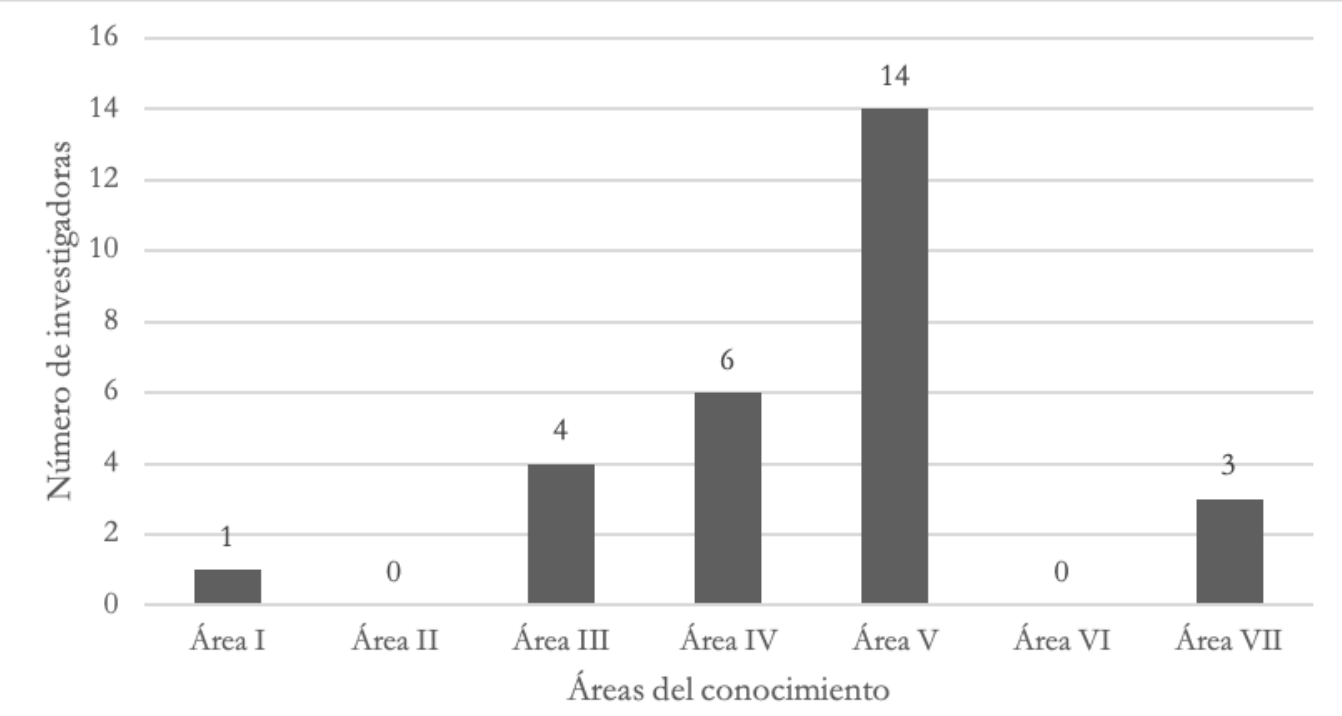

I. Físico-Matemáticas y Ciencias de la Tierra; II. Biología y Química; III. Medicina y Ciencias de la Salud; IV. Humanidades y Ciencias de la Conducta; V. Ciencias Sociales; VI. Biotecnología y Ciencias Agropecuarias; VII. Ingenierías

Fuente: Elaboración propia con base en la UP (2018)

Cabe resaltar que no hay participación en las áreas II. Biología y Química y VI. Biotecnología y Ciencias Agropecuarias. Coincidente con el hecho de que en la UP no hay licenciaturas ni posgrados que perfilen hacia esos campos del conocimiento. Contrastado con los investigadores varones de la UP, estos se distribuyen también mayormente en las áreas IV. Humanidades y Ciencias de la Conducta y V. Ciencias Sociales y en menor medida en el área I. Físico Matemáticas y Ciencias de la Tierra y en VII. Ingenierías, aunque cabe resaltar que en el área III. Medicina y Ciencias de la Salud las investigadoras duplican el número de investigadores (figura 7).

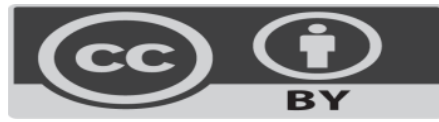




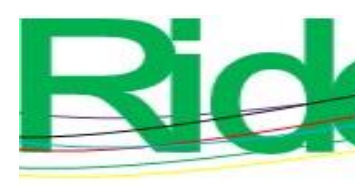

Revista Iberoamericana para la Investigación y el Desarrollo Educativo ISSN $2007-7467$

Figura 7. Distribución de los investigadores SNI de la UP por áreas de conocimiento

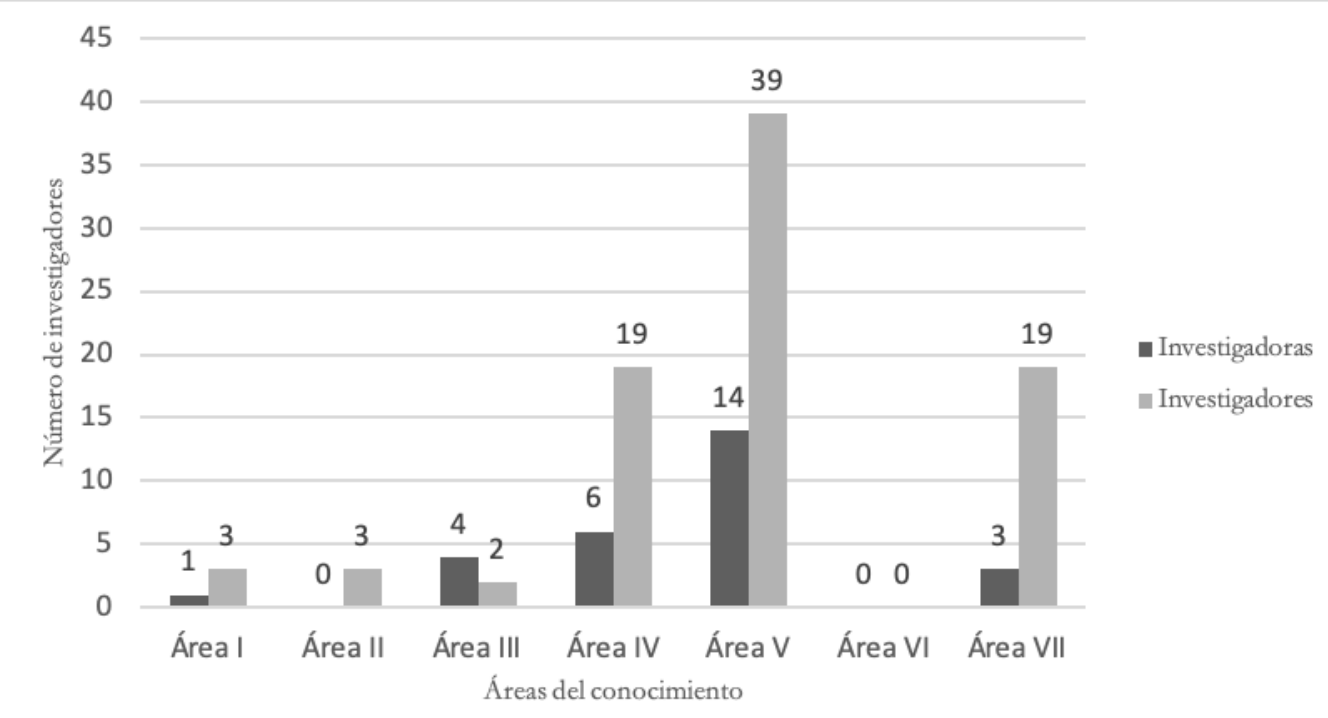

I. Físico-Matemáticas y Ciencias de la Tierra; II. Biología y Química; III. Medicina y Ciencias de la Salud; IV. Humanidades y Ciencias de la Conducta; V. Ciencias Sociales; VI. Biotecnología y Ciencias Agropecuarias; VII. Ingenierías

Fuente: Elaboración propia con base en la UP (2018)

\section{Participantes}

De las 28 investigadoras SNI con las que cuenta la UP, participaron en esta investigación 9, las cuales fueron elegidas por un muestreo no probabilístico, por conveniencia, respondiendo a los siguientes criterios: distintas áreas del conocimiento; edades y años trabajando en la universidad. Para conocer estos datos se aplicó un cuestionario vía electrónica, el cual fue respondido por 23 de las 28 investigadoras ( $82.1 \%$ ).

En cuanto a las áreas del conocimiento, siete pertenecen al área V. Ciencias Sociales, de las cuales dos pertenecen a la Escuela de Comunicación, dos a la Facultad de Derecho, dos a la Escuela de Económico-Empresariales y una a la Facultad de Ingeniería. Una al área IV. Humanidades y Ciencias de la Conducta, que está adscrita a la Facultad de Filosofía, y otra al área III. Medicina y ciencias de la salud, perteneciente a la Escuela de Medicina. Las edades fluctúan entre los 34 y 62 años. En tanto que los años trabajando en la UP van de 1 a 30. 


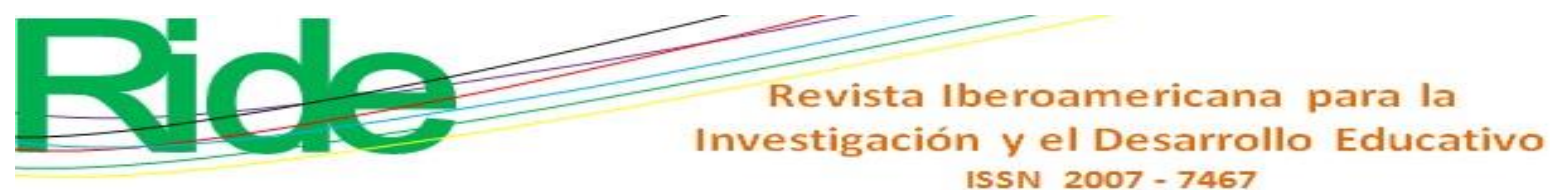

Otro dato de relevancia para esta investigación es que de las 9 entrevistadas 7 son casadas y con hijos de entre 6 meses y 18 años.

\section{Recopilación de la información}

Para la recopilación de la información se utilizó la técnica de la entrevista semiestructurada basada en las siguientes preguntas detonadoras: ¿qué retos has enfrentado para el ingreso, permanencia y promoción dentro del SNI?, ¿cómo has compaginado tu vida personal con tu labor como investigadora?, ¿cómo has compaginado otras actividades de tu vida profesional con tu labor como investigadora?, ¿cuáles han sido los apoyos que has recibido de tu universidad para ser investigadora?

Se realizaron nueve entrevistas de forma individual, pues, como sugiere Robles (2011), esto permite establecer un lazo de intimidad y complicidad con cada entrevistado de tal forma que comparten su experiencia con mayor confianza. Las entrevistas tuvieron una duración de entre 30 y 50 minutos y fueron grabadas en audio para su posterior transcripción. Lo anterior con el permiso de las entrevistadas para atender al criterio de confidencialidad.

\section{Análisis de la información}

Aun cuando el método cualitativo elegido para este trabajo es la fenomenología, se consideró para el análisis de la información la propuesta surgida desde la teoría fundamentada (Strauss y Corbin, 1998), que sugiere el método de las comparaciones constantes. La anterior decisión se tomó debido al siguiente apunte:

La naturaleza de las cuestiones de investigación guía y orienta el proceso de indagación y, por tanto, la elección [y combinación] de unos métodos u otros (...), los métodos de investigación surgen bajo las concepciones y necesidades de los investigadores que trabajan desde una disciplina concreta del saber (Rodríguez, Gil y García, 1999, pp. 40-41).

El método de las comparaciones constantes combina la codificación inductiva de categorías con la comparación constante entre ellas en tres momentos: la codificación abierta, la codificación axial y la codificación selectiva (Strauss y Corbin, 1998). Es así que después de leer varias veces 


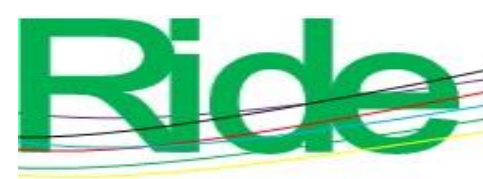

Revista Iberoamericana para la Investigación y el Desarrollo Educativo ISSN $2007-7467$

cada una de las entrevistas se identificaron unidades de significado, las cuales fueron agrupadas en categorías de análisis, que se interrelacionaron, integraron y refinaron en un mayor nivel de abstracción (Creswell, 2002). Para llevar a cabo lo anterior se siguió un proceso inductivo y dialéctico que se describe a continuación.

En un primer momento, se realizó una lectura detallada de las entrevistas con el fin de tener una idea general del contenido de estas e identificar las principales temáticas tratadas en el discurso de las protagonistas. Posteriormente, se llevó a cabo la segmentación en unidades de significado. Esta segmentación se hizo considerando los fragmentos que reflejaban ideas similares (codificación abierta). Cada unidad fue identificada con un número consecutivo y un identificador de la investigadora entrevistada, así I1 representa a la primera participante, I2 a la segunda, hasta I9 a la última.

A medida que se fue avanzando en el análisis e iban apareciendo nuevas unidades de significado se comparaban con las categorías previamente creadas para incluirlas en una de ellas. Si alguna de las unidades no coincidía con las ya creadas se definía una nueva categoría y se reubicaba (codificación axial). Finalmente, se llevó a cabo una depuración de los códigos creados y asignados a las unidades de significado, lo que permitió fusionar categorías semejantes y redefinir etiquetas que se adecuaran mejor al contenido.

Una vez que se hizo este procedimiento con cada una de las entrevistas y se alcanzó la saturación teórica (Strauss y Corbin, 1998), es decir, que no aparecieron unidades de significado distintas a las ubicadas en las subcategorías, categorías y metacategorías ya configuradas y estas tenían información variada y suficiente, se tomó la decisión de no realizar más entrevistas.

\section{Validez y credibilidad}

Lincoln, Lynham y Guba (2011) y Merriam y Tisdell (2016) proponen como formas de rigor metodológico el cuidado en la conceptualización, manejo de los datos y presentación de resultados. Para establecer la validez y confiabilidad de los resultados se realizaron los procedimientos que a continuación se describen: 

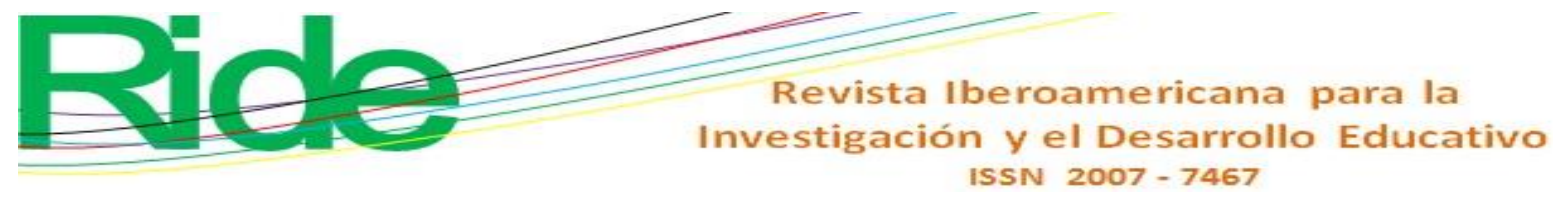

1) Una vez transcritas las entrevistas, las participantes tuvieron la oportunidad de revisarlas con la finalidad de que aprobaran o modificaran la información. Esta técnica es descrita por Lincoln y Guba (1985) como la más importante para establecer credibilidad.

2) Aunado a lo anterior, el proceso de categorización previamente descrito fue realizado de manera colegiada por las autoras de esta investigación y considerando el criterio de saturación teórica. Patton (2015) sugiere que la técnica de comparación que involucra a más de dos personas analizando datos y resultados promueve la credibilidad.

\section{Resultados}

Las participantes compartieron reflexiones acerca de sus experiencias personales y profesionales como investigadoras pertenecientes al SNI. Ellas percibieron algunos retos tanto a nivel personal como institucional y del propio sistema, además hablaron de cómo la cultura que privilegia a los varones tiene una influencia en su desarrollo como investigadoras.

Considerando los criterios de la saturación teórica antes descritos, en el análisis de la información emergieron dos metacategorías: lo personal y lo institucional, dentro de las cuales se generaron categorías y subcategorías, las cuales se pueden observar en el mapa semántico de la figura 8 . 
Figura 8. Categorías y subcategorías de análisis

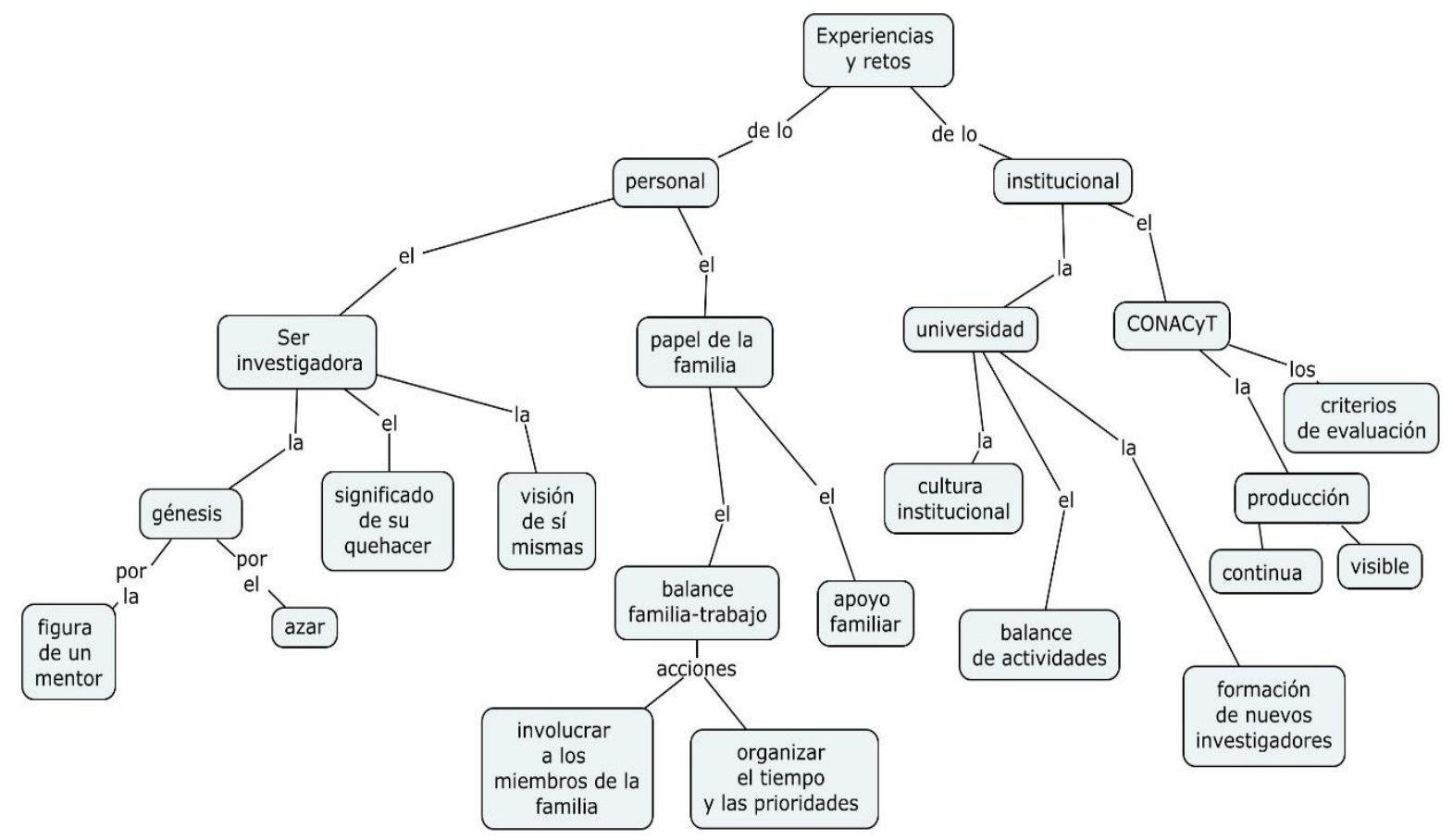

Fuente: Elaboración propia

Para la presentación de las categorías se seleccionaron las unidades de significado que mejor representan la idea propuesta.

\section{Sobre lo personal}

Esta metacategoría se compone de dos categorías. Por un lado, el ser mismo de la investigadora, en donde se hace referencia a las experiencias que han vivido las participantes y que las han llevado a convertirse en investigadoras, además del significado que tiene para ellas dedicarse a esto y cómo se definen a sí mismas dentro de esta labor. Por el otro, al papel de la familia, en la que se encontraron en un extremo las dificultades para lograr el balance entre la vida familiar y el trabajo, y en el otro la importancia del apoyo familiar en su carrera profesional. 


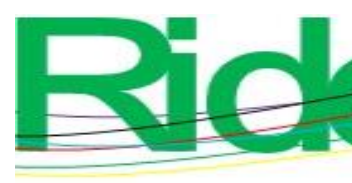

Revista Iberoamericana para la Investigación y el Desarrollo Educativo ISSN $2007-7467$

Dentro de la primera categoría, el ser mismo de la investigadora, una primera temática muestra la génesis de cómo se vislumbró el dedicarse a esto. En ella se encuentran dos tendencias. En primer lugar, la figura de un mentor que hace referencia a un profesor universitario, el cual inspiró la trayectoria profesional:

Mi decisión de ser investigadora la motivó una profesora de la licenciatura (...), empecé a trabajar con ella y vi lo que hacía y me parecía que era una mujer feliz, que estaba muy apasionada por lo que investigaba (...) y pensé que eso podría ser una forma de vivir, de hacer lo que te apasiona (I1).

En esa misma línea: “Cuando yo estudié la licenciatura había un profesor que me encantaba cómo daba la clase, que trabajaba cuestiones como de cine, entonces cuando terminé la licenciatura quería hacer una investigación sobre cine" (I4).

Y en segundo lugar, esta decisión es más resultado del azar y de una circunstancia coyuntural: "Inicié como investigadora más bien empíricamente porque dejé un puesto en el gobierno y decidí dedicarme a estudiar y a investigar y empecé a escribir" (I5). "Una vez titulada empecé a trabajar en una universidad como asistente de investigación, la verdad un poco por azar, entonces fue cuando empecé a conocer ese medio y a familiarizarme con él”(I8).

Más allá de las razones por las cuales decidieron ser investigadoras, cada una de las participantes le da un significado a su labor. A partir de ello se entiende a esta profesión como un trabajo arduo, de tiempo completo, que busca la incidencia en la sociedad mediante la generación de conocimiento, todo ello a partir de un continuo cuestionamiento de la realidad, en donde la responsabilidad juega un papel fundamental. "Es una carrera muy ardua que dura hasta tu último día pero que además construyes con muchísimos errores, tropiezos y luego te levantas y te dices que eso pasa" (I1).

Significa un trabajo de tiempo completo, es decir, todo el tiempo, aunque no estés haciendo investigación propiamente dicha, estás leyendo y estás pensando. Ves un fenómeno y dices "ahí está una cosa de investigación”, o sea, ya lo traes, es como un chip que te instalas en algún momento y ya todo lo ves con esos ojos (I4). 


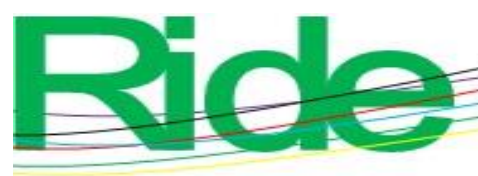

Revista Iberoamericana para la Investigación y el Desarrollo Educativo ISSN $2007-7467$

"Para mí ser investigadora es incidir positivamente en la sociedad" (I6). "Significa un reto, es la primera palabra que se me viene; significa aportar a la escalera referente al conocimiento; significa mucho trabajo y mucha dedicación" (I7).

No estar conforme, implica ese deseo de estar cuestionando las cosas de manera constante, de entender por qué o tal vez romper con estereotipos que tú tienes mentalmente. Ser investigadora también implica una responsabilidad, hay recursos limitados y por lo tanto es necesario que esos recursos se pongan a trabajar en cosas que vayan a ser de cierta relevancia (I9).

De igual forma compartieron que más que la genialidad, lo importante es la constancia y las horas dedicadas al trabajo de investigación. "Porque muchas veces no es la brillantez de la idea, sino la cantidad de horas que inviertes en una cosa" (I1).

Ahora bien, ¿cuál es la visión que tienen de sí mismas como investigadoras? Ellas se perciben como activistas orientadas a solucionar problemas del entorno bajo estándares de calidad.

No creo que tenga una solidez metodológica absoluta, pero sí creo que trato de ser profunda la investigación (...). Pero, además, yo creo que soy activista, porque también creo que como abogada, y si uno está en temas de telecomunicaciones que inciden en la sociedad, pues no puedes quedarte de brazos cruzados (I5).

"Yo me definiría como una investigadora que lo que busca es que se puedan aterrizar los productos de investigación" (I6).

Me defino como una investigadora que está haciendo cosas de calidad, está haciendo investigación de calidad. Pero que también como mujer, efectivamente, tienes muchos retos, porque tienes muchas trincheras que también tienes que cubrir y entonces es un desafío día a día (I7).

De acuerdo con el testimonio anterior, se trata de mujeres con distintos roles a los cuales atender, lo cual da pauta a la siguiente categoría, el papel de la familia en el desarrollo profesional, en donde consideran el balance de la vida familiar y del trabajo como un reto importante dentro de su trayectoria como investigadoras. "No es fácil, yo esposa, hijos, casa, trabajo y doctorado, pues era realmente difícil" (I2). "La incertidumbre sobre cómo sortear las dificultades de conciliar la vida familiar y laboral con este compromiso a cuestas me hizo difícil entregar la solicitud" (I1). 

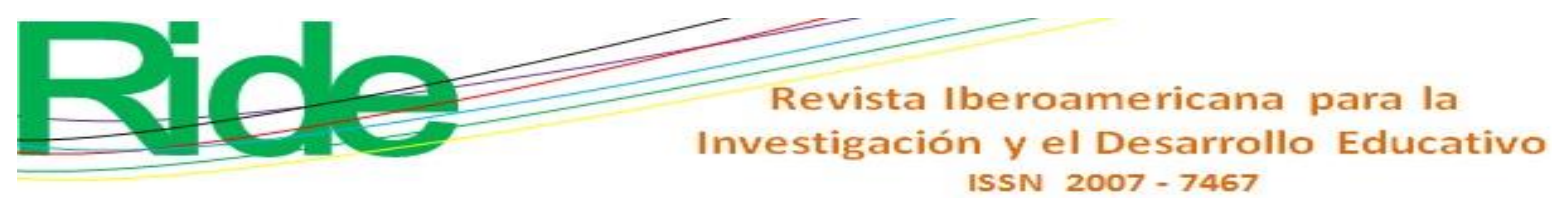

En lo personal, mi esposo no vive con nosotras, es militar, entonces soy como mamá soltera y tengo que atender a las niñas, venir a trabajar y dedicarme a la investigación (...). Lo difícil es que los hijos entiendan a lo que te dedicas: "mamá y qué estás haciendo", "es que tengo que entregar este trabajo", "pero ¿a quién le tienes que entregar?" (I4).

Sin embargo, para enfrentar estos retos han llevado a cabo ciertas acciones como involucrar a la familia en su vida académica: "Les expliqué [a mis hijos] qué es lo que iba implicar [aplicar al SNI). El más grande me preguntó que si me iban a dar dinero, y le dije que sí, y le pareció más interesante" (I1). "Mis hijos crecieron con ello, me vieron estudiar... sí, están muy acostumbrados a ver a sus madres estudiar, ir a congresos, están muy familiarizados [con la vida académica], para ellos es muy normal" (I2).

Hasta mis hijas me decían “oye, mamá, salieron unas películas de leones, ¿por qué no haces un trabajo sobre los leones en el cine? Porque mira, ya está El rey león, luego salió una italiana y entonces me decían: ya tienes dos películas más, por qué no haces una investigación (I4).

Al igual que organizar su tiempo y establecer prioridades:

Lo que traté fue aplicar, digamos, los conocimientos logísticos para lograrlo todo. Por ejemplo, vivo a una cuadra y media porque yo no podía permitirme robarles tiempo a mis hijos por estar en el tráfico, entonces toda la vida he comido con ellos (I6).

$\mathrm{Y}$ en ese mismo sentido:

El ser mamá me vuelve más eficiente en el uso de tiempo y entonces, como sé que son seis horas las que tengo, pues son seis horas que le tengo que sacar todo el jugo; igual y antes llegabas y te ponías a leer el periódico y estás que si los correos y ahorita es optimizar el tiempo (I9).

Aunado a dichas acciones, se encuentra el apoyo familiar que reciben, el cual no se reduce al cónyuge, sino que se amplía a la familia extensa, como los hermanos, los padres y los abuelos. 

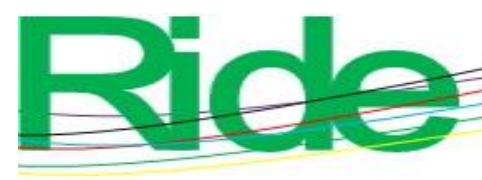

Revista Iberoamericana para la

Investigación y el Desarrollo Educativo

ISSN $2007-7467$

Me fui a vivir con mi mamá a la Ciudad de México para poder hacer el doctorado.

Siempre contra viento y marea. [Mi marido] se fue conmigo a la ciudad y estábamos él, mi hijo y yo. Y yo estudiando (I2).

"Lo que hemos hecho mi esposo y yo es alinearnos para convivir y al mismo tiempo quedarnos al cuidado de los hijos cuando el otro tiene que trabajar" (I6). "Mi esposo también afortunadamente me está apoyando mucho porque tiene mayor facilidad. Él me ha apoyado mucho en esta parte del manejo de los niños y demás cuestiones" (I7).

Ahorita mi hermana me ayuda a cuidar a la bebé y luego mi mamá va a tomar carga reducida de docencia y también me va a ayudar, sobre todo para que ella llegue a los seis meses y entonces ya entre a la guardería (I9).

"Dejé mucho tiempo a mis hijos, mi abuelo y mi marido me ayudaron, como para que no terminara, entonces lo terminé [el doctorado]" (I8).

Así como la familia se vislumbra como reto y como apoyo, el entorno institucional muestra también dos polos de un mismo fenómeno.

\section{Sobre lo institucional}

En la metacategoría de lo institucional, las investigadoras se enfrentan a la cultura y políticas de dos instituciones diferentes: la universidad a la que están adscritas y al propio SNI.

En cuanto a la universidad de adscripción, las participantes identifican tres principales retos: la cultura institucional, el balance en actividades de gestión, docencia e investigación y la formación de nuevos investigadores.

Las participantes describen que la cultura institucional sobre la investigación ha sido en muchas ocasiones un reto a resolver, pues la universidad surgió orientada a la docencia y se pensaba que la investigación era una actividad contingente y, por tanto, se carecía de apoyo.

La investigación se percibe como algo que haces porque te gusta, como un hobby, lo que haces en tus ratos libres, y creo que es normal porque esta universidad nació de las licenciaturas y está pensada muy desde la docencia (I1). 


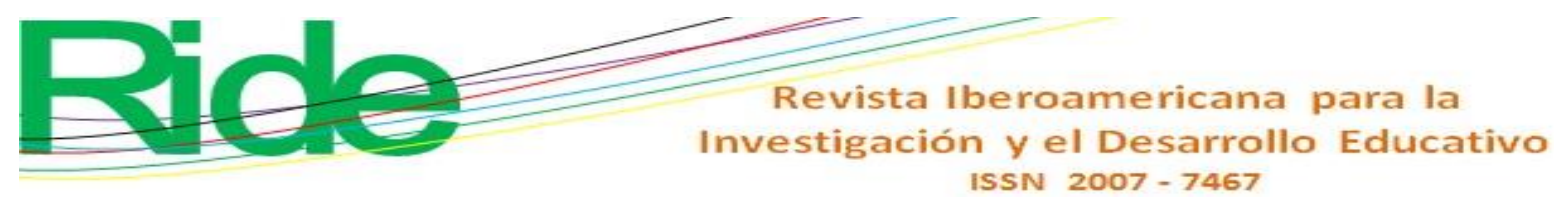

Y en ese mismo rubro:

Fue muy difícil, porque no entendían exactamente [los directivos], eran administrativos, sin menospreciar a nadie, ellos no veían la proyección de la universidad en la generación del conocimiento. No valoraban la importancia de la investigación. Afortunadamente todo ha cambiado para bien (I3).

Además:

El tema es que cuando estás en cargos administrativos tienes mucho movimiento durante el día, es decir, son llamadas, "bomberazos", y entonces para investigar necesitas tiempo de silencio, a solas, donde no suene el teléfono, porque también necesitas horas continuas (I6).

Sin embargo, también se percibe que las cosas están cambiando y se tiene mayor apoyo institucional, pues se han generado políticas que benefician el hacer de los investigadores.

Se me ha hecho menos complicado a partir de esta serie de políticas en donde me permiten dedicarle horas exclusivamente a la investigación (...). Yo estuve trabajando en cargos de gestión, pero justo cuando entré al SNI me los quitaron (I4).

"Si yo les dijera que quiero hacer un freno a la carrera administrativa para dedicarme más a la investigación, yo creo que no habría problema (...). Entonces, en ese sentido, yo me siento totalmente apoyada" (I6).

Aunque las políticas han ayudado a mejorar las condiciones institucionales para el desarrollo de la investigación, todavía queda por resolver el tema de la formación de nuevos investigadores, puesto que la universidad cuenta con pocos doctorados y la mayoría de las maestrías son profesionalizantes, por lo que las participantes tienen gran dificultad para tener tesistas. "La dirección de tesis, porque no son muchos los alumnos de posgrado, y no todos optan por hacer tesis" (I8). "Ahora que la universidad provee otras formas de titulación, las tesis caen a cuenta gota y eso choca mucho con lo que se está esperando de nosotros en el SNI, porque el SNI te pide formar recursos" (I9).

A las cuestiones institucionales de la universidad se suman los criterios que el SNI promueve.

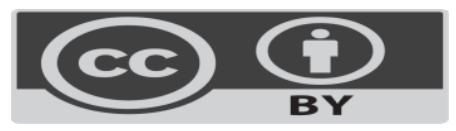


El SNI tiene por objeto fortalecer la calidad de la investigación. La evaluación que promueve afecta la dinámica tanto de las instituciones de educación superior como de los académicos. Uno de los mayores retos, según las participantes, sigue siendo el mantener una producción continua y de calidad que sea publicada en revistas internacionales, arbitradas e indexadas. "Definitivamente es un reto tener una producción continua y 'cierta' producción, es decir, un quehacer dentro de determinados parámetros" (I3). "Pues yo creo que los retos tienen que ver con incrementar la producción, que ahí también, pongámoslo entre paréntesis, la universidad plantea Scopus, y algunas de esas cosas que están en Scopus pues no están en Conacyt” (I4). “Tienes que aprender a decir cuántos voy a publicar, en qué revistas, buscar tu información, ajustarte a los tiempos, juntar la cantidad que te pide Conacyt si quieres subir, o si quieres mantenerte" (I8).

Además, las investigadoras comparten que se exige una producción visible que sea citada por otros colegas. Ante este criterio de visibilidad surge otro reto: "No tengo a demasiada gente que me cite porque en México [mi tema] es poco explorado; creo que es una de las razones por las que no he podido subir de nivel en el SNI" (I3).

Tienes que pedirles a los juzgadores que cuando te hayan citado, a las autoridades que te avisen; y entonces terminas dedicándole un mes de tu vida a ver quién te cita, y entonces el argumento contrario es "pues escribe en Scopus”, pero no es tan fácil porque si no es open source, quién te cita. Mis obras más citadas son mis libros que yo tengo ahí abiertos (I5).

En referencia a los criterios de evaluación del SNI, se encontraron aspectos tanto positivos como negativos. En cuanto a los positivos, las participantes comparten cómo el sistema les ayuda a enfocar la investigación. "[El sistema] está muy bien armado y pensado para que funcione, porque [pide] redes de investigación, docencia, divulgación, ir a congresos, formar nuevos investigadores" (I1).

Ir aprendiendo a que debes de ser medido, que nos cuesta y que cuando te miden, tú mismo te pones tus metas, o sea, de decir: este año voy a tratar de publicar cuatro, ya sabes que de esos cuatro a lo menos no te aceptan dos y dos van a estar en proceso, entonces de repente también te das cuenta que tienes que, pues, ser eficiente (I8). 

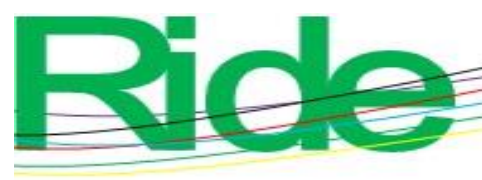

Revista Iberoamericana para la

Investigación y el Desarrollo Educativo

ISSN $2007-7467$

Por otro lado, en los aspectos negativos, las investigadoras reconocen que los criterios del SNI encorsetan a la investigación.

Pues como en cualquier sistema de evaluación y acreditación, el SNI ordena acciones y metas de manera que el trabajo de investigación, y las publicaciones, se orientan a los propios requisitos del Conacyt, y no siempre a lo que el investigador desea hacer (I3).

Además de los retos mencionados, las participantes describen cómo la cultura que privilegia al varón permea en el ámbito académico y científico, lo cual crea una carga extra a los retos ya presentados.

Pero lo que yo creo es que en general la investigación, las líneas de la investigación, han nacido de mentes masculinas, ha habido poca participación de las mujeres y nosotras tenemos una voz muy distinta que aportar... También pienso, se lo dije a mi jefe en su momento, me que pagaba como doctora y no como doctor (I1).

"Siento que las mujeres normalmente tenemos más cargas administrativas, pero es porque somos muy buenas, entonces sí ves hombres que quizá tienen mucho tiempo libre y tú estás llena de miles de cosas" (I6).

Aunque también algunas investigadoras reconocen que ha habido ciertos avances en este sentido:

Cualquiera que piense en los discursos de género puede ver, pero yo creo que hay otras cosas que generalmente no se dicen, en el SNI sí hay una licencia para la maternidad, sin goce de estímulo económico, pero la hay (I1).

Otro testimonio menciona lo siguiente respecto a este mismo punto: "Mi jefe me apoyó siempre, había quien se oponía porque decían que no iba a regresar, es mujer, no es cabeza de familia, porque era casada, etc." (I2).

Una vez presentado el análisis de la información, a continuación se da paso a las consideraciones finales que emergieron de la interpretación de los resultados. 


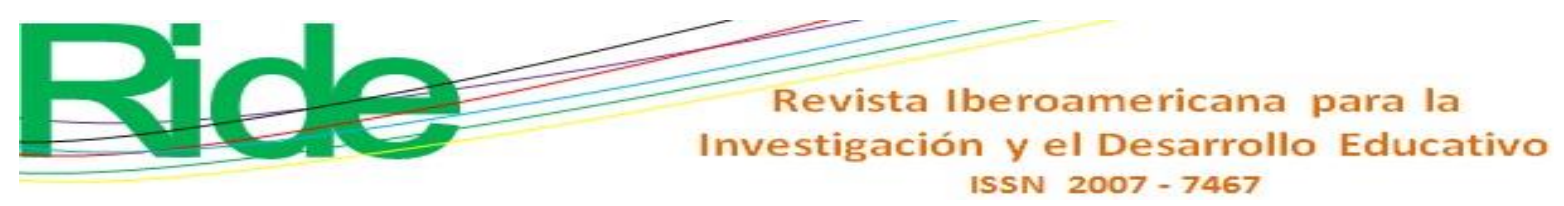

\section{Consideraciones finales}

Si bien existen trabajos sobre mujeres investigadoras en el ámbito de las universidades públicas, el espacio de las particulares se muestra como un área de oportunidad. Es así como este estudio resulta ser una primera aproximación para dar respuesta a esta brecha en el conocimiento. Dentro de los hallazgos más relevantes en torno a las experiencias y los retos de las investigadoras SNI, se puede decir que, tanto en universidades públicas como en particulares, las mujeres encuentran un reto en el balance de la vida familiar y del trabajo, tal y como queda patente en la categoría del papel de la familia, en donde se hace referencia a las dificultades en este ámbito.

Sin embargo, las entrevistadas han superado dicho reto con acciones como involucrar a la familia, organizar el tiempo y las prioridades, aunque lo más importante ha sido contar con el apoyo familiar, lo cual contrasta con otras realidades mostradas en la literatura, en donde las mujeres expresan no contar precisamente con este soporte.

Pasando al actuar profesional, se presentan dos retos comunes: las dificultades para la producción científica y la formación de nuevos investigadores, que en las universidades públicas se dan por la falta de tiempo como consecuencia de actividades como la maternidad y la atención a la familia. Mientras que, en este caso de estudio, lo primero es consecuencia de los tiempos para la revisión, publicación e indexación; y lo segundo, por la falta de posgrados orientados a la investigación en la universidad de adscripción.

Otro aspecto que resulta distinto entre las universidades públicas y este caso de estudio es en relación con el rango de edad dentro del SNI, el cual oscila entre los 45 y los 55 años, y aunque la media de edad de las mujeres SNI de este estudio es de 47 años, resalta la participación de 5 investigadoras menores a los 35 años.

Después de haber hecho una comparación entre experiencias y retos de las investigadoras en las universidades públicas y este caso, a saber, sobre una universidad particular, ahora se hará referencia a cómo la universidad donde se lleva a cabo el estudio ha ido modificando la cultura en torno a la investigación y, por tanto, creando políticas institucionales favorecedoras de dicha práctica. Lo anterior resulta evidente en la información vertida en las entrevistas en donde las investigadoras con mayor trayectoria dentro de la universidad muestran agrado al ver cómo están cambiando las cosas, mientras que para las nuevas resulta natural dicho apoyo.

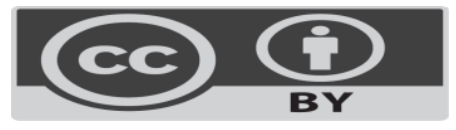




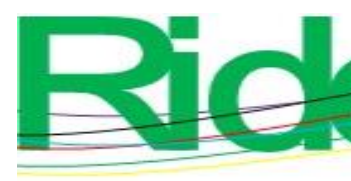

Revista Iberoamericana para la

Investigación y el Desarrollo Educativo

ISSN $2007-7467$

La acción detonadora fue la creación en 2016 de la Dirección Institucional, de las vicerrectorías en cada campus y de las secretarías de investigación en cada escuela y facultad. A partir de dicha organización, se empezaron a configurar políticas para incentivar la producción científica visible, para apoyar proyectos de investigación mediante un fondo anual en el que se presentan estos para evaluación y posterior apoyo. Además de la creación de un repositorio institucional para la divulgación de la producción científica de la universidad y el desarrollo del Sistema de Gestión para la Investigación.

No obstante los esfuerzos realizados en este rubro que han permitido fortalecer las prácticas de investigación en la universidad, todavía quedan pendientes líneas de acción para atender los retos manifestados por las investigadoras, como la formación de nuevos investigadores.

Por otro lado, en cuanto a futuras líneas de investigación, queda en el tintero en un primer momento darles voz a los investigadores para de esta forma conocer sus experiencias y retos, y en un segundo momento, realizar un estudio comparativo entre mujeres y hombres, e identificar diferencias y semejanzas.

\section{Referencias}

Cano, G. (2010). La polémica en torno al acceso de las mujeres a las profesiones entre los siglos XIX y XX. En MacGregor, J. (comp.), Miradas sobre la nación liberal: 1848-1948. Proyectos, debates y desafios (pp. 169-192). Ciudad de México, México: Universidad Nacional Autónoma de México.

Castañeda, M. y Ordorika, T. (coords.) (2015). Investigadoras en la UNAM: trabajo académico, productividad y calidad de vida. México: UNAM-Centro de Investigaciones Interdisciplinarias en Ciencias y Humanidades.

Castillo, R. (2018). Diferencias visibles e invisibles de las mujeres en la ciencia. Universidad Nacional de San Agustín de Arequipa, Perú, 2017. Revista ciencias sociales, 40, 79-97. Recuperado de http://revistadigital.uce.edu.ec/index.php/CSOCIALES/article/view/1251.

Cetina, E. A. (17 de junio de 2015). Conferencia inaugural. Ponencia presentada en el Encuentro Internacional de Investigadores. Diálogos Multidisciplinarios en Escenarios de Innovación en la Educación Basada en Competencias. Guerrero, 17 de junio de 2015.

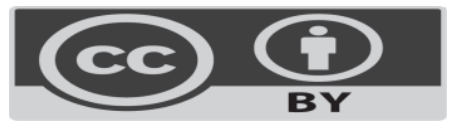




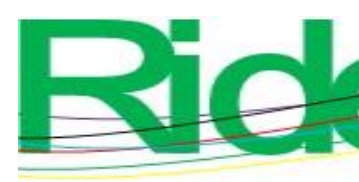

Revista Iberoamericana para la

Investigación y el Desarrollo Educativo

ISSN $2007-7467$

Creswell, J. C. (2002). Educational research. Planning, conducting, and evaluating quantitative and qualitative research. New Jersey, United States: Merrill Prentice Hall.

Diario Oficial de la Federación [DOF]. (2018). Reglamento del Sistema Nacional de Investigadores.

Recuperado

de

http://www.dof.gob.mx/nota_detalle.php?codigo=5513525\&fecha=16/02/2018.

Díaz de Kuri, M. (2009). Margarita Chorné y Salazar la primera mujer titulada en América Latina. México: Demac. Recuperado de http://demac.org.mx/wpcontent/uploads/2015/12/MARGARITA-CHORNE.pdf.

Didou, S. y Gérard, E. (2010). El Sistema Nacional de Investigadores, veinticinco años después. La comunidad científica, entre distinción e internacionalización. México: Asociación Nacional de Universidades e Instituciones de Educación Superior (Anuies).

Galaz, J. F., Gil, M., Padilla, L. E., Sevilla, J. J., Arcos, J. L. y Martínez, J. G. (coords.) (2012). La reconfiguración de la profesión académica en México. México: Universidad Autónoma de Sinaloa-Universidad Autónoma de Baja California. Recuperado de https://www.ses.unam.mx/publicaciones/index.php?seccion=libro\&id=34

Galeano, M. (2004) Diseño de proyectos en la investigación cualitativa. Colombia: Fondo Editorial Universidad EAFIT.

García, M. (2015). Reflexiones sobre los retos para ingreso, permanencia y promoción en el SNI de las investigadoras. En Mendieta, A. (coord.), ¿Legitimidad o reconocimiento? Las investigadoras del SNI. Retos y propuestas (pp. 29-35). Puebla, México: Benemérita Universidad Autónoma de Puebla-Ediciones La Biblioteca. Recuperado de http://www.inb.unam.mx/historias_noticias/2015/sni_retospropuestas_15.pdf.

González, R. (2006). Las mujeres y su formación científica en la ciudad de México. Siglo XIX y principios del XX. Revista Mexicana de Investigación Educativa, 11(30), 771-795. Recuperado de http://www.redalyc.org/pdf/140/14003004.pdf.

Grediaga, R. (2001). Retos y condiciones de desarrollo: la profesión académica en México en la última década. Revista Mexicana de Investigación Educativa, 6(11), 95-117. Recuperado de http://www.redalyc.org/pdf/140/14001107.pdf.

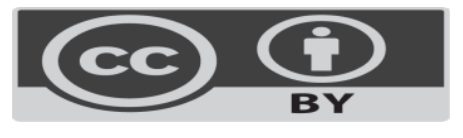




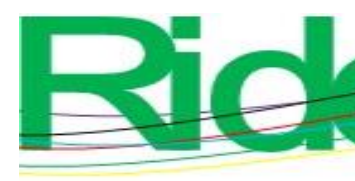

Revista Iberoamericana para la

Investigación y el Desarrollo Educativo

ISSN $2007-7467$

Lincoln, Y. S., Lynham, S. A. and Guba, E.G. (2011). Paradigmatic controversies, contradictions, and emerging confluences, revisited. In Denzin, N. and Lincoln, Y. S. (eds.), The Sage handbook of qualitative research (pp. 97-128). California, United States: Thousand Oaks Sage.

Lincoln, Y. S. and Guba, E. G. (1985). Naturalistic inquiry. California, United States: Thousand Oaks Sage.

Macías, G. y Islas, C. (2018). Las mujeres y la sociedad del conocimiento: uso y aplicabilidad de las TIC por las investigadoras. Revista de Estudios de Género. La Ventana, 48, 208-235. Recuperado de https://dialnet.unirioja.es/descarga/articulo/6494940.pdf.

Mendieta, A. (coord.) (2015). ¿Legitimidad o reconocimiento? Las investigadoras del SNI. Retos y propuestas. México, Puebla: Benemérita Universidad Autónoma de Puebla-Ediciones La Biblioteca.

Recuperado

de http://www.inb.unam.mx/historias noticias/2015/sni retospropuestas 15.pdf.

Merriam, S. and Tisdell, E. (2016). Qualitative Research: a guide to design and implementation ( $4^{\text {th }}$ ed.). San Francisco, United States: Jossey-Bass.

Muñiz, E. y Ramos, M. (2019). Presión social para ser madre hacia mujeres académicas sin hijos. Nóesis. Revista de Ciencias Sociales y Humanidades, 28(55). Recuperado de https://doi.org/10.20983/noesis.2019.1.4.

Ordorika, I. (2015). Equidad de género en la educación superior. Revista de la Educación Superior, 2(174), 7-17. Recuperado de http://www.ses.unam.mx/integrantes/uploadfile/iordorika/Ordorika2015 EquidadDeGene roEnLaEducSup.pdf.

Patton, M. Q. (2015). Qualitative research and evaluation methods ( $4^{\text {th }}$ ed.). California, United States: Sage.

Piñera, D. (2002). La educación superior en el proceso histórico de México. México: Poderes de Jalisco.

Ranero, M. (2018). Mujeres y academia en México: avances, retos y contradicciones. EduScientia, 1(1), 72-88. Recuperado de http://www.eduscientia.com/index.php/JOURNAL/article/view/33.

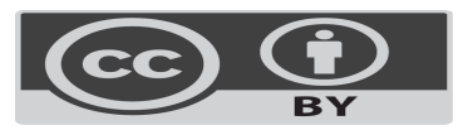



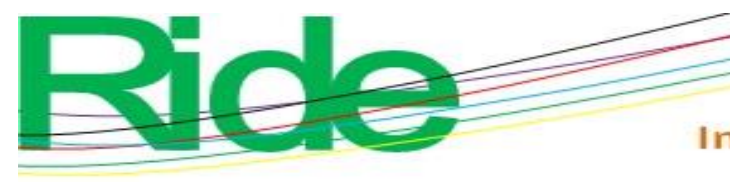

Revista Iberoamericana para la Investigación y el Desarrollo Educativo ISSN $2007-7467$

Robles, B. (2011). La entrevista en profundidad: una técnica útil dentro del campo antropofísico. Revista $\quad$ Cuicuilco, $\quad$ 18(52), 39-49. Recuperado de http://www.redalyc.org/pdf/351/35124304004.pdf.

Rodríguez, G., Gil, J. y García, E. (1999). Metodología de la investigación cualitativa. Málaga, España: Aljibe.

Ruiz, R. (2012). El Sistema Nacional de Investigadores. En Vega, S. (coord.), Sistema Nacional de Investigadores. Retos y perspectivas de la ciencia en México (pp. 41-48). México: UAMXochimilco.

Recuperado https://issuu.com/acdovala1/docs/sni_retos_y_perspectivas_de_la_cien.

Sánchez, V. (7 de enero de 2015). Mujeres en la ciencia en México. Agencia informativa Conacyt. Recuperado de http://www.conacytprensa.mx/index.php/ciencia/66-sociedad/politicacientifica/390-las-mujeres-en-la-ciencia.

Sistema Nacional de Investigadores [SNI]. (2017) Investigadores vigentes 2017. México: Sistema Nacional de Investigadores. Recuperado de https://www.conacyt.gob.mx/index.php/elconacyt/sistema-nacional-de-investigadores/archivo-historico.

Strauss, A. and Corbin, J. (1998). Basics of qualitative research. Techniques and procedures for developing grounded theory ( $2^{\text {nd }}$ ed.). California, United States: Sage Publications.

Taylor, S. y Bogdan, R. (1987). Introducción a los métodos cualitativos de investigación. Buenos Aires, Argentina: Paidós.

Tójar, J. (2006). Investigación cualitativa, comprender y actuar. Madrid, España: La Muralla.

Universidad Panamericana [UP]. (2018). Censo registrado en la Dirección Institucional. México: Universidad Panamericana. 


\begin{tabular}{|c|c|}
\hline Rol de Contribución & Autor (es) \\
\hline Conceptualización & Mónica del Carmen Meza Mejía \\
\hline Metodología & Sara Elvira Galbán Lozano igual, Claudia Fabiola Ortega Barba Igual \\
\hline Software & NO APLICA \\
\hline Validación & NO APLICA \\
\hline Análisis Formal & Sara Elvira Galbán Lozano igual, Claudia Fabiola Ortega Barba Igual \\
\hline Investigación & $\begin{array}{l}\text { Mónica del Carmen Meza Mejía igual, Sara Elvira Galbán Lozano igual, } \\
\text { Claudia Fabiola Ortega Barba igual }\end{array}$ \\
\hline Recursos & NO APLICA \\
\hline Curación de datos & Mónica del Carmen Meza Mejía \\
\hline $\begin{array}{l}\text { Escritura - Preparación } \\
\text { del borrador original }\end{array}$ & $\begin{array}{l}\text { Mónica del Carmen Meza Mejía igual } \\
\text { Sara Elvira Galbán Lozano igual } \\
\text { Claudia Fabiola Ortega Barba Igual }\end{array}$ \\
\hline $\begin{array}{l}\text { Escritura - Revisión y } \\
\text { edición }\end{array}$ & $\begin{array}{l}\text { Mónica del Carmen Meza Mejía igual } \\
\text { Sara Elvira Galbán Lozano igual } \\
\text { Claudia Fabiola Ortega Barba igual }\end{array}$ \\
\hline Visualización & Mónica del Carmen Meza Mejía \\
\hline Supervisión & Mónica del Carmen Meza Mejía \\
\hline $\begin{array}{l}\text { Administración de } \\
\text { Proyectos }\end{array}$ & $\begin{array}{l}\text { Mónica del Carmen Meza Mejía igual } \\
\text { Claudia Fabiola Ortega Barba igual }\end{array}$ \\
\hline Adquisición de fondos & Mónica del Carmen Meza Mejía \\
\hline
\end{tabular}

